PERVERSOS EFEITOS DOS ENCARGOS FINANCEIROS NO PREÇO DA VENDA

\author{
Autor: Paulo José Francisco de Macedo \\ Ex-aluno do curso de pós-graduação \\ em Contabilidade Da FEA/USP
}

\title{
Perversos Efeitos dos Encargos Financeiros no Preço de Venda
}

O presente trabalho pretende mostrar os efeitos perversos dos encargos financeiro na estrutura de formação nos preços de venda no Brasil.

Nossa Legislação Contábil contribui decisivamente na ocorrência desses efeitos, uma vez que trata os encargos financeiros como um componente indivisível em relação aos preços, admitindo como integrante do custo final de produção.

Assim, muito embora encargo financeiro nada tenha a ver com custo de produção pois, trata-se de um custo decorrente do financiamento de capital, de acordo com nossa atual legislação ele é tratado como custo e, por conseguinte objeto de contabilização como estoque/custo de produção vendido. Evidentemente que estamos nos referindo aos encargos financeiros embutidos no preço de venda e cobrados pelo vendedor, pois os encargos cobrados pelas instituições financeiras são contabilizados como tais e não objeto de inclusão nos custos de produção.

Isto não nos parece correto: a mesma verba ter tratamento diferente, só porque são diferentes, só porque diferentes são seus financiadores! Afinal, somente porque um é banco e o outro não, a verba deve ser tratada diferente, embora tenha a mesma finalidade, ou seja, a remuneração de capital?

A arrecadação de ICMS, PIS, FINSOCIAL, IPI e outros impostos direitos tem certamente um grande interesse nesta situação e, até mesmo por isto, é impossív el que as autoridades econômicas tenham dificuldades em altera-la, pois não temos a pretensão de acreditar que estas autoridades não tenham se apercebido desta distorção elementar.

Mas, se por um lado à arrecadação destes tributos se beneficia desta anomalia, por outro lado o país perde muito com a sua manutenção. O efeito multiplicador que esta regra causa na cadeia de preços é simplesmente monumental. Os preços são triplicados numa velocidade absurda, os ganhos também o são e, podemos assegurar, nem todos os empresários deste país entendem este fenômeno com clareza. Alguns simplesmente ganham mais até mesmo sem esperar e sem compreender exatamente porque. Outros se aproveitam de uma certa dose de complexidade que 0 assunto apresenta para daí tirar proveitos.

Não temos a pretensão de esgotar o assunto e, para fazer um exemplo prático do que defendemos, vamos tomar a hipótese de uma cadeia produtiva que envolva três empresas, sendo (a empresa 3) aquela que vende o produto ao consumidor.

Com estas três empresas vamos fazer um ensaio, admitindo na primeira situação, que os encargos financeiros cobrados pelo vendedor obedeçam que se dispõe nossa atual legislação ou seja, integre o custo de aquisição do comprador e passe a fazer parte assim do seu custo de aquisição do comprador e passe a fazer parte assim do seu custo de produção. Na outra situação, vamos admitir que pudéssemos contabilizar os encargos financeiros numa conta de resultados, sem transita-la pelo custo de produção.

Nosso exemplo tem ainda como premissa que o "mark-up" de todas as empresas é o mesmo e foi obtido pela seguinte formula:

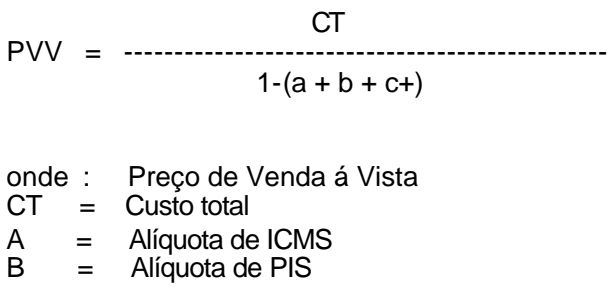


C = Alíquota de Finsocial

$\mathrm{D}=$ Taxa de Lucro

Assim considerando um lucro de 20\%, nosso "Mark-up" será calculado em:

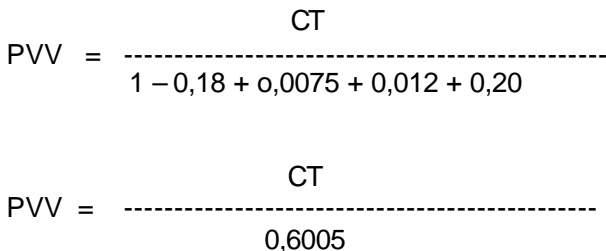

Como a formula acima nos mostra apenas o Preço de Venda à Vista, vamos admitir, para efeito deste estudo, um encargo financeiro de $25 \%$ a.m. e considerar que o prazo concedido pelo vencedor pelo vendedor seja sempre de 30 dias (se o prazo for maior, evidentemente as distorções serão maiores). Portanto:

$P V P=P V P x(1=i)$

Onde:

PVP = Preço de Venda a Prazo

$\mathrm{I}=$ Taxa de Encargos Financeiros

Assim teremos:

$P V P=P V V \times 1,25$

Vamos ainda admitir um IPI, médio de $10 \%$ que será calculado sobre o preço final de venda, seja à vista, seja a prazo. Assim o PVV = PV x 1,10, onde:

$\mathrm{PFV}=$ preço final de venda (a vista ou a prazo)

Outra hipótese que vamos assumir neste trabalho é de que cada empresa da cadeia produtiva exemplificada utiliza sempre o mesmo custo de mão-de-obra (para simplificar o exemplo), ou seja, $\operatorname{Cr} \$ 50,00$. Aliás, esta hipótese não fica distante na realidade, pois quanto mais próximo das empresas distribuidoras, menor é a participação dos custos de mãode-obra no seu custo total. Nas empresas que iniciam o ciclo certamente a participação é maior.

Vamos então ao caso, admitindo que o custo da matéria-prima da empresa 1 é de CR $\$ 100,00$ (sem IPI) e onde estão inclusos $18 \%$ de ICMS e $25 \%$ de encargos financeiros.

\section{HIPÓTESE 1 - ENCARDOS FINCEIROS INCLUSOS}

\begin{tabular}{|c|c|c|c|}
\hline Discriminaçāo & Empresa 1 & Empresa 2 & Empresa 3 \\
\hline $\begin{array}{l}\text { Materia-prima } \\
\text { Măo-de-obra }\end{array}$ & $\begin{array}{l}82,00 \\
50,00\end{array}$ & $\begin{array}{r}225: 32 \\
50: 00\end{array}$ & $\begin{array}{r}527,25 \\
50,00\end{array}$ \\
\hline custo Total & 132.00 & 275,32 & 577.25 \\
\hline$P \vee V$ & 219.82 & 458,48 & 961.28 \\
\hline ICMS Incluso & 39.57 & 85,52 & 173,03 \\
\hline$P \vee P$ & 274,78 & 573,10 & 1201.60 \\
\hline ICMS Incluso & 49.46 & 103.16 & 216.29 \\
\hline$D V P C / I P I$ & 302.46 & 630,41 & - \\
\hline
\end{tabular}

No Custo de matéria prima da empresa 3 está incluindo o IPI por tratar-se de empresa distribuidora, que por não ter direito à manutenção do crédito repassa-o ao consumidor final.

Vimos, portanto, pelo exemplo acima, que os preços ao consumidor calculados pela empresa 3 são os seguintes:

À vista .................... $\$$. 961,28

A prazo.................. $\$ \quad 1.201,60$

Para melhor testar o nosso modelo, vamos apurar os resultados das empresas: 


\begin{tabular}{|c|c|c|c|}
\hline Descricao & Empresa 1 & Empresa2 & Empresa3 \\
\hline$\underset{(-) \text { Vendas }}{\text { IPrutas }}$ & $\begin{array}{r}302: 26 \\
27: 48\end{array}$ & $630: 41$ & $1.201,60$ \\
\hline Vendas s/ IPI & 274.78 & 573.10 & 1.201 .60 \\
\hline ( $(-)$ ICMS PISINSOC. & $\begin{array}{r}49: 46 \\
5: 36\end{array}$ & $\begin{array}{r}103: 16 \\
11: 18\end{array}$ & $216: 29$ \\
\hline Vendas Ilquilass & 219.96 & 458.76 & 961.88 \\
\hline Custo Prod. Vena. & 132.00 & 275.32 & 577.25 \\
\hline margem Bruta & 87.96 & 183,44 & 384,63 \\
\hline Encargos Financ. & - & - & - \\
\hline Lucro Ifquido & 87.96 & 183,44 & 384.63 \\
\hline $\begin{array}{l}\text { z Lucro Liquido } \\
\text { s/ vendas g/IPI }\end{array}$ & 327 & $32=$ & 328 \\
\hline
\end{tabular}

Alguma conclusão pode obter, de imediato, com o modelo acima:

1- O lucro planejado de $20 \%$ sobre o valor das vendas S/IPI se transformou em $32 \%$. Isso porque estamos cobrando de nosso cliente25\% a.m. de encargo financeiro embutido no preço de venda, sem levar em conta que a parte deste valor está sendo financiado pelo nosso fornecedor cujos encargos financeiros já integram o nosso custo de aquisição. Estamos assim, cobrando do nosso cliente duas vezes o mesmo valor, ou seja, através dos $\operatorname{Cr} \$ 82,00$ da matéria-prima e através do $25 \%$ que acrescentamos ao preço a vista para vender a prazo.

2- Possivelmente algum empresário nem se perceba deste fenômeno e acredite estar ganhando $20 \%$ mesmo, atribuindo a outro fator qualquer o resultado maior. Outros, no entanto, usando de subterfúgios continuaram provando, através de suas planilhas de custo, como fizemos no enunciado do problema, que o seu lucro é efetivamente aquele que foi planejado. Afinal, como é que se pode ter certeza de que quais cargos e quais encargos financeiros estão considerados nos preços de compra de todo um "Mix" de matériasprimas destas empresas? É muito fácil adotar o numero que seja conveniente a cada situação.

Vamos tomar agora a mesma cadeia produtiva, com as mesmas premissas, admitindo, contudo, que os encargos financeiros pagos e cobrados fossem considerados, separadamente, apurando-se um resultado financeiro liquido na formação dos preços de venda.

Nesta hipótese, os encargos financeiros pagos são computados fora do custo de produção, em conta especifica, onde serão também creditados os encargos financeiros cobrados do cliente, apurando-se assim, um resultado liquido.

\begin{tabular}{|c|c|c|c|}
\hline Discriminação & Empresa 1 & Empresa 2 & $E=p r e s a l$ \\
\hline $\begin{array}{l}\text { Matéria-prima } \\
\text { Măo-de-obra }\end{array}$ & $\begin{array}{l}62: 00 \\
50: 00\end{array}$ & $144: 54(1)$ & 291:57 (2) \\
\hline Custo Total & 112,00 & 194.54 & 341,57 \\
\hline P V V & 186.51 & 323.96 & 568,81 \\
\hline Incluso & 33,57 & 58,23 & 102.39 \\
\hline Enc.Fin-Inclusos & 46.63 & 80,99 & 242.20 \\
\hline$P V P$ & 233,14 & 404,95 & 711.01 \\
\hline ICMS Incluso & 41.97 & 72.89 & 127.98 \\
\hline IPI & 23.31 & 40.50 & - \\
\hline$P V P C / I P I$ & 256,45 & 445.45 & 711,01 \\
\hline
\end{tabular}

(01) $233,14-41,97$ de ICMS - 46, 63 de Encargo Financeiro

(02) 445, 45-80, 99 - 72, 89 (IPI considerado como custo)

Pelo quadro acima podemos verificar que os preços ao consumidor a serem praticados pela empresa 3 , são substancialmente menores do que os preços da hipótese anterior os desavisados poderiam concluir que as empresas desta hipótese estão perdendo dinheiro e que seus preços estão subestimados.

No entanto isto não é verdade! No primeiro quadro a seguir vamos demonstrar os resultados destas empresas considerando os encargos financeiros contabilizados no custo da matéria-prima, como determina nos sa legislação contábil e fiscal,(muito embora tenham sido excluídos na formação do preço de venda como mostra o quadro acima.)

No segundo quadro a seguir vamos mostrar como ficaria a demonstração de resultados se os encargos financeiros pagos e cobrados fossem contabilizados numa conta separada de encargos financeiros líquidos. 
ENCARGOS FINANCEIROS INCLUIDOS NO CUSTO DA MATÉRIA-PRIMA

\begin{tabular}{|c|c|c|c|}
\hline Denoriģan & Eapresa 1 & Capresa 2 & Kapresa , \\
\hline $\begin{array}{l}\text { Vondas Brutas } \\
(\rightarrow) \text { IPI }\end{array}$ & $\begin{array}{r}286,45 \\
23,31\end{array}$ & $\begin{array}{r}445,45 \\
46,50\end{array}$ & $\pi 11.01$ \\
\hline Venese of IDI & 233,14 & 404,25 & 711,01 \\
\hline $\begin{array}{ll}\Leftrightarrow(-) & 10 \times 5 \\
\Leftrightarrow & \text { DIS/FINSOC. }\end{array}$ & $\begin{array}{r}41,97 \\
4,55\end{array}$ & $\begin{array}{r}72,99 \\
7,90\end{array}$ & $\begin{array}{r}127,98 \\
13,86\end{array}$ \\
\hline Fondsen Luquidas & 186,63 & 324,16 & 569,27 \\
\hline Cunto Prod. Vend. & 132,00 & 241,27 & 422,56 \\
\hline Kargen Bruta & 34,02 & 82,93 & 146,61 \\
\hline Encarqes rinase. & - & $=$ & - \\
\hline Lecro Liquido & 54,62 & 82,99 & 246,62 \\
\hline 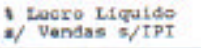 & 238 & $20 t$ & 208 \\
\hline
\end{tabular}

\section{ENCARGOS FINANCEIROS CONTABILIZADOS EM CONTA SEPARADA}

\begin{tabular}{|c|c|c|c|}
\hline Descriqua & Eapresa 1 & maptesa 2 & Eapresa 3 \\
\hline $\begin{array}{l}\text { Yendas Brutss } \\
(\rightarrow) \text { IDI }\end{array}$ & $\begin{array}{r}209,82 \\
23,31\end{array}$ & $\begin{array}{r}364,46 \\
40,50\end{array}$ & $56 a$, at \\
\hline Vendas $a / I P I$ & 186,51 & 323,96 & 568,81 \\
\hline 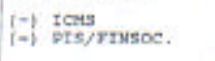 & $\begin{array}{l}41,97 \\
4,55\end{array}$ & $\begin{array}{r}72,99 \\
7,90\end{array}$ & $\begin{array}{l}127,98 \\
13,26\end{array}$ \\
\hline Vendal tiguidas & 120,09 & 243,17 & 426,27 \\
\hline Culto prad. Vend. & 112,00 & 194,54 & 341,57 \\
\hline Maryes bruta & 27,09 & $\$ 4,63$ & 85,40 \\
\hline Ene.Finan.21q. $\{2\}$ & 26.63 & 24,26 & 81,22 \\
\hline Lucto Lfquitus & 34,62 & 82,99 & 146,62 \\
\hline $\begin{array}{l}\text { I: Margon } \\
\text { s/ Vendis s/TPI }\end{array}$ & 158 & 158 & $15 x$ \\
\hline $\begin{array}{l}\text { if tucro Liguido } \\
\text { s/ Vendas } \$ / \text { IPI }\end{array}$ & 291 & 201 & 208 \\
\hline
\end{tabular}

(1) Neste caso os encargos financeiros a serem cobrados do cliente, embora façam parte do preço de venda a prazo, não são contabilizados na conta de venda, mas na conta de Encargos Financeiros Líquidos onde serão compensados com os encargos financeiros pagos na compra da matéria-prima.

(2) Encargos Financeiros Líquidos: Encargos Financeiros cobrados do cliente menos os Encargos Financeiros pagos ao vendedor da matéria-prima. Assim:

$$
\begin{array}{ll}
\text { Empresa 1 } & =46,63-20,00=26,63 \\
\text { Empresa 2 } & =80,99-43,63=34,36 \\
\text { Empresa 3 } & =142,20-80,99=61,21
\end{array}
$$

Observa-se neste último quadro uma redução da margem para 15\%. Isto acontece porque calculamos os impostos sobre o Preço de Venda a Prazo, fazendo-os incidir também sobre os encargos financeiros ali inclusos mas contabilizados separadamente da conta de vendas.

Desta feita, podemos verificar que quando os impostos calculados são relacionados com o preço a vista, observa-sequea relação entre eles difere de suas alíquotas, pois foram calculados sobre os preços de Venda a Prazo. Esta redução na margem é recomposta benevolamente, porém, pelo resultado positivo da conta de Encargos Financeiros Líquidos.

Essa hipótese 2 nos mostra de forma clara o efeito multiplicador que os encargos financeiros exercem sobre os preços, em nossa economia. Vejamos as diferenças de preços entre uma e outra hipótese :

\begin{tabular}{|c|c|c|c|}
\hline $\begin{array}{c}\text { Preço de Venda } \\
\text { a prazo s/IPI }\end{array}$ & Hipótese 1 & Hipótese 2 & $\begin{array}{l}\text { Acrescimo \& } \\
\text { entre H1 e H2 }\end{array}$ \\
\hline Empresa 1 & 274,78 & 233,14 & $17,86 \%$ \\
Empresa 2 & 573,10 & 404,95 & $41,52 \%$ \\
Empresa 3 & $1.201,60$ & 711,01 & $69,00 \%$ \\
\hline
\end{tabular}

O efeito multiplicador aqui é de $69 \%$ sobre o preço de venda ao consumidor praticado pela empresa 3 . 
Evidentemente, este efeito pode ser maior, se maiores forem às taxas de encargos financeiros. Pode ser maior ainda mesmo com a taxa de $25 \%$ a.m. , quando as empresas procuram proteger os encargos financeiros cobrados de seus clientes das incidências de ICMS, PIS, FINSOCIAL, IPI e outros, fazendo com que o valor dos encargos financeiros cobrados sejam tais que, deduzido destes impostos, mantenham uma taxa liquida de $25 \%$ a.m.

Vejamos como fica nossa hipótese 1, quando é adotado este procedimento.

ENCARGOS FINANCVEIROS DA INCIDENCIA DE IMPOSTOS DIRETOS

\begin{tabular}{|l|c|c|c|}
\hline Descrição & Empresa 1 & Empresa 2 & Empresa 3 \\
\hline $\begin{array}{l}\text { Materia-prima } \\
\text { Må-de-obra }\end{array}$ & $\begin{array}{c}82,00 \\
50,00\end{array}$ & $\begin{array}{c}236,55 \\
50,00\end{array}$ & $\begin{array}{c}576,14 \\
50,00\end{array}$ \\
\hline Custo Total & 132,00 & 286,55 & 626,14 \\
\hline PV V & 219,82 & 477,19 & 1042,70 \\
\hline ICM Incluso & 39,57 & 85,89 & 187,69 \\
\hline Enc. Financ. (*) & 68,66 & 149,05 & 325,69 \\
\hline PV P & 288,48 & 626,24 & 1368,39 \\
\hline ICM Incluso & 51,93 & 212,72 & 246,31 \\
\hline IPI & 28,85 & 62,62 & - \\
\hline PV P C/IPI & 317,33 & 688,86 & 1368,39 \\
\hline
\end{tabular}

(*) $25 \%+$ ICMS $=$ IPI + FINSOCIAL $(0,25 / 0.8005)$

Nesta situação o preço de Venda a Prazo ao consumidor, na empresa 3 é ainda maior. Se o compararmos com o mesmo preço calculado pela hipótese 2, encontraremos um multiplicador de $92 \%$. A margem de lucro, por sua vez, subirá para $34 \%$ mas, o que é mais importante: O valor absoluto deste lucro subirá de $\operatorname{Cr} \$ 384,63$ para $\operatorname{Cr} \$ 469,26$ (acréscimo de $\operatorname{Cr} \$ 84,63$ ou $22 \%)$.

Aqui vale uma observação importante: qualquer mecanismo que faça o preço final aumentar, mesmo que a percentagem de lucro se mantenha fixa, aumentará o valor absoluto deste lucro. (É simples: 20\% de 100 é igual a 20 porém, 20\% de 150).

Assim, aos mais astutos interessam mecanismos que "engordem" os preços porque assim seus lucros seriam maiores e defendem argumentando que suas margens não foram alteradas (Margens percentuais, evidentemente).

Voltando porém a nossa hipótese 2, podemos observar que um simples procedimento que isole os encargos financeiros pagos da estrutura de formação do preço de venda não só causa uma justa redução das margens de lucro, como também evita uma desenfreada multiplicação de preços.

Para regularizar este procedimento, nossas autoridades deveriam, no mínimo, exigir que as empresas não computassem os encargos financeiros nos custos de matéria-prima quando formulassem suas planilhas de custo. $\underline{Q}$ ideal, porém, seria a alteração de nossas leis Contábeis e fiscais permitindo-se que os encargos financeiros decorrentes de prazos concedidos nas vendas fossem cobrados fora da fatura de venda mercantil.

Isto provocaria, uma redução na arrecadação dos impostos diretos que, de alguma forma, poderia ser compensada por tributos a serem cobrados na operação financeira (sobre encargos financeiros cobrados incidir-se-ia algum tributo a ser criado).

A possibilidade de uma evasão fiscal, com a adoção deste procedimento, seria evitada com normas rigorosas e uma delas delas, deveria ser a de não se permitir cobrança de encargos financeiros a taxas superiores àquelas praticada no mercado financeiro. (Isto evitaria evasão fiscal dos impostos diretos: ICMAS, PI, FINSOCIAL, IPI, etc.)

A regulamentação deste assunto, permitindo-se a cobrança de encargos financeiros decorrentes de concessão de prazos de pagamento nas operações de venda, fora da fatura mercantil, viria facilitar sobremaneira a contabilização e controle de custos em nossas empresas.

O quadro a seguir mostra como ficaria a nossa cadeia de preços, caso a matéria fosse regulamentada conforme propomos: 


\begin{tabular}{|c|c|c|c|}
\hline Diecri=fnaçio & Emprosa 1 & Eyprass 2 & Expresa I \\
\hline $\begin{array}{l}\text { Kateria-prina } \\
\text { Yao-de-obrs }\end{array}$ & $\begin{array}{l}65,20 \\
50,00\end{array}$ & $\begin{array}{r}159,15 \\
50, \infty 0 \\
\end{array}$ & $\begin{array}{r}318,44 \\
50,00\end{array}$ \\
\hline Cuate Total & 125.60 & 207,05 & 368,44 \\
\hline DV v & 192.50 & 340,13 & 013.56 \\
\hline TCNS Inelues & 34,65 & 62,30 & 120,44 \\
\hline $1>1$ & 10,28 & 34,61 & - \\
\hline PWV COM IRt & 211,75 & 380,74 & 611,56 \\
\hline $\begin{array}{l}\text { Ene, Finane, náo } \\
\text { Inel. no prepo }\end{array}$ & 48,13 & $86,5]$ & 153,39 \\
\hline $\begin{array}{l}\text { Custo rinal } \\
\text { oprazo para o } \\
\text { souprador }\end{array}$ & 250,88 & 667,27 & 766,95 \\
\hline
\end{tabular}

Obs. :Embora os encargos financeiros devessem ser calculados sobre o preço com o IPI, procuramos manter a mesma regra dos exemplos anteriores que é a maneira mais visual adotada pelas empresas no tratamento desta verba, calculada sobre o preço com ICMS e depois acrescido do IPI.

Um fato curioso pode ser verificado de imediato neste caso: É que os preços de venda aqui, já a partir da empresa 1, são ,maiores que os preços de venda aqui, já a partir da empresa 1, são maiores do que os da hipótese 2 anterior. Isto ocorre porque o ICMS a menor que se calcula na empresa vendedora proporcionará também um crédito menor na empresa compradora, fazendo com que o custo da matéria-prima adquirida seja maior. Neste caso, a redução de ICMS e demais impostos diretos seriam transferidos para o lucro das empresas, caso se fossem adotados mecanismos de ajustes. Evidentemente que na hipótese de adoção de uma legislação com base neste modelo, dever-se-ia prever tais mecanismos, que seriam aplicados com todo o rigor, sob pena de se permitir um ganho adicional às empresas.

O quadro seguinte nos mostra quais seriam os lucros destas empresas caso não fossem adotados os indispensáveis ajustes a que nos referimos:

\begin{tabular}{|c|c|c|c|}
\hline Descrip̧ão & Empresa 1 & Empresa 2 & Empresa 3 \\
\hline $\begin{array}{l}\text { Vendas Brutas } \\
(-) \text { IPI }\end{array}$ & $\begin{array}{r}211,75 \\
19: 25\end{array}$ & $\begin{array}{r}380,74 \\
34: 61\end{array}$ & 613,56 \\
\hline Vendas $s / I P I$ & 192,50 & 346,13 & 613.56 \\
\hline $\begin{array}{l}(\because) \text { ICMS } \\
(-) \text { PIS/FINSOC. }\end{array}$ & $\begin{array}{r}34,65 \\
3,75\end{array}$ & $\begin{array}{r}62,30 \\
6,75\end{array}$ & $\begin{array}{r}110,44 \\
11,96\end{array}$ \\
\hline Vendas Liquidas & 154,10 & 277,08 & 491,26 \\
\hline custo prod. vend. & 115.60 & 207.85 & 368,44 \\
\hline Margem Bruta & 38,50 & 69.13 & 122.72 \\
\hline Enc. Finan. Liq. & 28,13 & 38,40 & 66,86 \\
\hline Lucro Ifquido & 66.63 & 107.53 & 189,58 \\
\hline $\begin{array}{l}\text { * Margem } \\
\text { s/Vendas s/IPI }\end{array}$ & $20 \%$ & $20 \%$ & 208 \\
\hline $\begin{array}{l}\text { s Lucro Liquido } \\
\text { s/ Vendas s/IPI }\end{array}$ & 34,58 & 318 & 318 \\
\hline
\end{tabular}

Certamente que o lucro apurado permitira a adoção de mecanismos que reduzam os preços. Porém, para melhor entendermos o problema, devemos observar que o ganho financeiro previsto no exemplo acima só será possível se a empresa dispuser de "capital de giro" suficiente para "bancar" o seu cliente por trinta dias, caso contrario, terá que recorrer a capital de financiamento e, neste caso, o custo que resultar deste financiamento será debitado à conta de Encargos Financeiros Líquidos.

Para concluir este nosso trabalho e, como resultado das questões aqui avaliadas, queremos deixar algumas reflexões finais, a propósito da matéria:

1) A abertura de transformação de preço na economia brasileira aborda de forma incorreta os encargos financeiros pagos pela obtenção de prazos concebidos no pagamento de insumos, classificando-os como custo de produção.

2) Como decorrência observa-se um efeito multiplicador perverso na formação dos preços de venda, muitas vezes não compreendido ou considerado por nossas empresas.

3) Este efeito multiplicador age de forma impiedosa sobre os preços de venda, gerando mais inflação, especialmente quando as taxas de juros são ascendentes.

4) Estas distorções são causadas com a convivência e estimulo da legislação fiscal e contábil, uma vez que não se é permitido cobrar encargos financeiros sobre vendas a prazos desvinculados da Nota Fiscal/ Fatura. Assim, estes encargos integram o preço de venda e, portanto, são contabilizados pelo comprador como custo dos insumos adquiridos.

5) Além do efeito multiplicador a que nos referimos, o procedimento permite que os encargos financeiros decorrentes do financiamento de capital de giro dos compradores sejam repassados, em cadeia, aos preços de

\section{Caderno de Estudos, São Paulo, FIPECAFI - Setembro/1991}


venda, sem afetar as margens de lucro. Assim mesmo a empresa descapitalizada e que necessita de capital de giro de terceiros, matem intacta sua margem de lucros obtendo a mesma margem que uma empresa contabilizada.

6) Como encargos financeiros incorporados ao preço de venda, quanto maior for a taxa financeira ou o prazo concedido, maior será o preço final ao consumidor e, assim, maiores serão as margens de lucro de cadeia produtiva, pois estas margens são fixadas em valores percentuais $(10 \%, 15 \%, 20 \%$, etc.) aplicadas a um preço final. Esta é uma incomoda situação para nossa economia.

7) Com a contabilização dos encargos financeiros separadamente do preço de venda, as margens de lucro absurdamente elevadas (e, quase sempre, financiadoras da baixa produtividade) tenderão a se reduzir, uma vez que os preços serão menores. As empresas com deficiência de capital de capital de giro terão que deduzir das suas margens os encargos financeiros pagos, como remuneração do capital de terceiros e não mais poderão acrescentar estes custos aos seus, para obtê-los de volta adicionalmente à margem planejada. As empresas capitalizadas obterão, evidentemente, um resultado financeiro positivo como remuneração do seu capital empregado, mantendo intactas as margens previstas.

8) Na situação proposta a avaliação do efeito alavancagem financeira será de grande importância, o que não acontece na situação atual, uma vez que com o procedimento hoje adotado, esta alavancagem é sempre favorável.

9) Efetivamente haverá, na hipótese de adoção do procedimento proposto, uma redução na arrecadação de impostos diretos que poderá ser compensada com maiores volumes de vendas e com um imposto a ser criado e calculado sobre os encargos financeiros cobrados na concessão de prazos de pagamentos.

10) Para evitar evasões fiscais as taxas cobradas não poderiam superar as médias praticadas pelo mercado financeiro.

11) Na implantação do sistema haveria mecanismos de ajustes que evitariam a transferência de tributos para as margens de lucro das empresas. 